\title{
Academics and Learners' Perceptions on Blended Learning as a Strategic Initiative to Improve Student Learning Experience
}

\author{
Adeline $\mathrm{Ng}$ Ling Ying ${ }^{1 \mathrm{a}}$, Irene Yang ${ }^{1}$ \\ ${ }^{1}$ Swinburne University of Technology Sarawak, Malaysia
}

\begin{abstract}
The increasingly tighter shift of socio-economic constraints on higher education sectors in the recent years has called for greater flexibilities in student learning experience both locally and abroad. To this end, we have recently implemented a Blended Learning Initiative in an attempt to provide better learning support and greater flexibility to our students. This initiative is also in line with the University's aim of having $50 \%$ of our learning and teaching delivered on-line by 2020. In this report, we present our findings on academics and learners' perceptions on the approach which were obtained through surveys. Results showed that blended learning approach was new to the academics and the factors for successful blended learning implementation were identified. Results also showed that learners appreciated the approach as it made learning more accessible and flexible. Furthermore, they also enjoyed the interesting online activities incorporated into their units. In addition, learners were also able to review and pace their own learning. They also perceived that they have the access to the resources and technical ability to cope with online learning materials and activities. Nonetheless, the survey also revealed that learners still prefer to have academics delivering information to them directly rather than a flipped classroom model. In conclusion, findings from this study provide insights that blended learning could be effective to supplement courses offered by the faculty.
\end{abstract}

\section{Introduction}

With the emergence of technology, universities are currently embracing transformation in learning delivery. In fact, incorporating technology into education is essential to address diverse needs of learners. For instance, learners may differ in terms of education background, abilities, culture and learning preferences. As learners' needs were being identified, there is a need to seek an effective approach to facilitate quality learning.

Blended learning is an innovative instructional approach which combines several delivery strategies of online and face-to-face components [1]. Interactive capabilities of information and communication technologies (ICTs) in blended learning offer the opportunities to increase flexibility of access to learning resources and enhance self-directed learning at any time and pace. When thoughtfully integrating ICTs in blended learning, this learning approach as indicated in various researches has significant education implications due to its effectiveness for course delivery in higher education. Specifically, there is evidence that overall students enrolled in blended classes achieve higher grades than their counterparts in fully online or face to face courses [2]. Likewise, student satisfaction also tends to be higher in blended courses when compared to traditional lecture courses [3].

Due to the praises blended learning has received, many higher learning institutions are now shifting towards implementing blended learning as a strategic initiative to improve student learning experience. There is compelling evidence of significant growth of blended learning in the last decade with the increase of theoretical studies in journal articles published as early as 1996 [2, 4]. Recognizing the benefits of blended learning in education, it was emphasized as one of the key ideas in the Malaysian Education Blueprint 2015 - 2025 [5] to enhance the quality of learning and teaching through the use of Open Education Resources (OER), Open Course Ware (OCW) and Massive Open Online Courses (MOOC) from renowned higher education institutes.

The university uses ICTs in learning and teaching ever since it was established 16 years ago. The learning management system (LMS) adopted was Blackboard. It is a learning platform that allows academics to communicate with learners, monitor learners' participation while assessing their performance. The university requires all instructional materials to be uploaded on Blackboard for learners to access online. Besides that, Blackboard is also used to manage grades for a course by using the online grade center tool. This tool efficiently reduces double handling work and students could access their results and feedback easily. In addition, the management also uses Blackboard as the formal platform for making announcement. Some academics have also taken a step further to create online assessments and student forums on Blackboard. These approaches have the potential to motivate students to

a ang@swinburne.edu.my 
engage in learning while monitoring their progress in an ongoing manner.

Although blended learning has the potential to increase quality of learning, integration of technology in learning requires clear understanding of pedagogical goals. In other words, educators need to select suitable instructional technology to assist students in achieving the learning objectives while providing them with the best possible learning and teaching experiences. The attempt to use technology tools as a delivery vehicle without educational goal is bound to fail. Besides that, there must also be an alignment of goals at all levels of an institution from senior administration to students for successful implementation of blended learning [6,7].

As most studies on blended learning reported were from the United States and Australia [2-4, 6-7], it is crucial to study and understand the perceptions and factors contributing to its success locally. Consequently, a working group was established to start a Blended Learning Project spearheaded by the Faculty of Engineering, Computing and Science to determine academic staff and student perceptions on blended learning and also to identify the factors for successful implementation in the local environment.

\section{Blended learning project}

The transition to adopt and implement blended learning in learning and teaching in the faculty started in year 2014 as a strategic initiative to align course delivery with its main campus in Melbourne. The primary aim was to improve student learning experience and to provide students with more flexible and interactive modes of delivery.

As a start, two units were selected to trial blended learning delivery. These units were first year common units with a large number of students. The components identified as beneficial to be delivered online were ongoing assignments and tutorials. Instead of the traditional physical assignments, online practice quizzes were created. The quizzes were rolled out after each topic were delivered and the questions were taken from a pool of online multiple choice questions (MCQ) which were created and randomized in Blackboard. Each online assignment was opened to students for a week and students were allowed multiple attempts. The rationale behind this approach was to encourage learners to have more practice and to familiarize themselves with the concepts applied. Since MCQ assignments were used in Blackboard, marking for the assignments was automated and students could receive immediate feedback on their understanding of the topics. Furthermore, automated marking also avoided ongoing workload for academics.

In addition to online assessments, tutorial videos were also recorded using the Camtasia recording software and posted on Blackboard for students to review at their convenience. This enabled students to pace their own learning and was especially useful in large scale classes of students with diverse learning abilities and background. The recorded videos also facilitated to reduce the workload of academics who only need to present only once.

In 2015, three other units were identified to implement blended learning in the unit delivery. Besides online assignments and recorded videos, online discussion boards and student forums were created on Blackboard for information sharing and peer review. This environment motivated learners to have an ongoing and active engagement through collaborative learning as learners communicate to discuss their work using the Blackboard platform. Students were also introduced and provided the link to relevant videos and reading materials available on the OER. The purpose was to foster students' learning about the topics discussed. Additionally, technology tools such as iPad and Clickers were also applied in classes to attract and engage students. All the efforts mentioned above were used as supplement and did not replace any contact hours in class.

\section{Research objective and methodology}

This study aims to evaluate both academics and learners' perceptions on blended learning in the university. This investigation will provide better understanding of factors and issues to be considered when adopting blended learning.

Academics' perceptions survey on blended learning was conducted in the beginning of the implementation of blended learning. The survey was rolled out to a focus group. The aim of the survey was to investigate academics' understanding and to identify the types of support they require in the implementation of blended learning. The survey was divided into two sections; qualitative and quantitative. The quantitative section consisted of four Likert items on a scale rated from 1 to 5 ("Strongly Disagree" to "Strongly Agree").

On the other hand, students' perceptions survey was conducted to investigate their learning experiences in blended learning activities. The survey was conducted at the end of the semester. The students' satisfactions were determined from different perspectives such as motivation, technical support, and flexibility and preparation time. Similar to the academics' perceptions survey, the students' perceptions survey was also divided into two sections; qualitative and quantitative, measured with the same Likert scale rated from 1 to 5 ("Strongly Disagree" to "Strongly Agree").

\section{Results and discussions}

\subsection{Academics' perceptions on blended learning}

Although advances in technology provide opportunities for academics to design and deliver their courses in ways that support and enhance a teacher's role, the integration of technology in blended learning has also changed the role expectations of teachers and students. According to Norberg, Dziuban \& Moskal [8], teachers embraced new role as facilitators and students had access to seemingly 
limitless source of informational assets through the internet. Conversely, leaders of educational institution are challenged to meet the demands to facilitate meaningful learning outcomes. Hence, Garrison \& Kanuka [1] emphasized that a clear institutional direction is vital to successfully adopt blended learning initiative.

According to the feedback from the academics' perceptions survey, most academics responded that they were new to blended learning and had never implemented blended learning initiative in their units. The implementation of blended learning is certainly a new challenge for most educators as they have to change their delivery method to accommodate the use of technology. Hence, it was not surprising that some academics had expressed drawbacks to the implementation of blended learning.

In the survey, some academics had also expressed concern that technology will gradually substitute teachers in learning institution. Academics lacked understanding that even though technology seems to be a powerful and engagement tool, if it is not tied with pedagogical principles, learning will remain futile. Besides that, another concern raised was that blended learning approach would increase academics' workload as learning, planning and implementation stage would require significant amount of effort and time. In addition, academics' also perceived that courses which require more technical or practical skills would be harder to teach online, whereas less technical courses would be wellsuited to the blended environment.

Moreover, it is important to take all other stakeholders' expectation into consideration. These include the requirements of professional bodies and the expectation of parents in education. Academics were concerned that the implementation of blended learning will affect learners' feedback with regards to teaching and learning at the end of the semester. As a result, they were hesitant to introduce and employ blended learning in their units. Nonetheless, they agreed that blended learning made learning more accessible and flexible to students. It could also increase student engagement in learning and in the long run, blended learning is time and cost effective compare to traditional face-to-face learning environment.

Apart from academics' understanding of blended learning, other factors which determine the successful implementation of blended learning were also identified through the survey. Most academics perceived themselves as beginners in the use of technology tools in teaching and learning activities. Some lacked technology skills and thought that it would be a challenge to apply the approach in their unit delivery. Thus, there is a need for academic support in the use of technology in order to implement blended learning.

The types of support that academics expect in the implementation of blended learning are shown in Table 1. Specifically, they require a dedicated personal to assist them to gain experience with technology. Apart from this, they would also like to have professional development training and workshops in designing blended activities and the use of technology. In addition to the support, it is also essential for academics to have adequate access to infrastructures and technology tools in the faculty for implementation.

Table 1. Descriptive statistics for types of support in the implementation of blended learning.

\begin{tabular}{|l|c|c|}
\hline \multicolumn{1}{|c|}{ Items } & Mean & $\begin{array}{c}\text { Standard } \\
\text { deviation }\end{array}$ \\
\hline 1) Educational support group & 4.00 & 0.93 \\
\hline 2) Library and media specialists & 4.13 & 0.64 \\
\hline $\begin{array}{l}\text { 3) Professional development and } \\
\text { training/workshop in designing } \\
\text { blended module and the use of } \\
\text { technology }\end{array}$ & 4.13 & 0.99 \\
\hline 4) Demo/sharing/learning session & 4.13 & 0.99 \\
\hline
\end{tabular}

In conclusion, although the adoption of blended learning has the potential to enhance quality of delivery in learning, academics' perceptions survey revealed some concerns with regards to blended learning. These concerns were similar to the major barriers in technology integration such as: 1) resources, 2) educator's knowledge and skills and 3) educator's attitudes and beliefs [9]. In fact, the most notable concern was related to the availability of essential resources which include (a) access to technological tools; (b) technical and learning instruction support (c) professional development training and preparation time [10].

\subsection{Learners' perceptions on blended learning}

Learners showed positive responses to the blended learning initiative applied in the two trial units identified in 2014. The components identified as beneficial to be delivered online were ongoing assignments and tutorials. Due to these blended learning activities, learners were able to pace their own learning as they had flexible access to the learning resources they required. Besides that, they were also able to review and test their understanding of a topic whenever they needed. As automated marking on Blackboard was used, learners were also able to get feedback and grades on their assignments immediately.

In 2015, the blended learning approach was introduced to the whole faculty and three additional units were selected to participate in the delivery method. The participants were undergraduate degree students who enrolled in the respective units in the faculty. The type of blended learning activities implemented in the units include online quizzes, videos, online forum or discussions, online peer feedback and use of technological tools such as iPad and Clickers.

The descriptive statistics for items (mean and standard deviation) with regards to the blended learning activities in the three units were shown in Table 2. It is essential to obtain learners' feedback on their learning experience from the aspect of resources, content, design of the blended learning activities to identify areas for future improvements. 
Table 2. Descriptive statistics for blended learning activities.

\begin{tabular}{|l|c|c|}
\hline \multicolumn{1}{|c|}{ Items } & Mean & $\begin{array}{c}\text { Standard } \\
\text { deviation }\end{array}$ \\
\hline 1) Accessibility and flexibility & 4.00 & 0.84 \\
\hline 2) Self-directed learning & 3.88 & 0.87 \\
\hline 3) Motivation & 3.42 & 0.91 \\
\hline 4) Content (interesting) & 3.75 & 0.90 \\
\hline $\begin{array}{l}\text { 5) Resources (technological } \\
\text { tools and access to study) }\end{array}$ & 4.30 & 0.72 \\
\hline 6) Technical ability & 3.83 & 0.85 \\
\hline 7) Preparation time & 3.60 & 0.89 \\
\hline $\begin{array}{l}\text { 8) Preferences over face-to- } \\
\text { face instruction }\end{array}$ & 3.07 & 0.95 \\
\hline $\begin{array}{l}\text { Overall Satisfaction of } \\
\text { Blended Learning Activities }\end{array}$ & 3.93 & 0.76 \\
\hline
\end{tabular}

According to the survey, most learners reacted positively to the blended learning initiatives applied in the units as shown in Table 2 with overall satisfaction mean score of 3.93. Blended learning activities allowed learners to access learning resources and receive online feedback easily. This is especially helpful as the classes here were dominated by Asian students. The students rarely volunteer to ask or answer a teacher's question in class.

According to Lee [11], the concept of "face" which is associated with pride and self- esteem is related to this phenomenon. The learners' lack of confidence to speak in class may be due to one of these three conditions: (1) students are afraid of losing face if they provide a wrong answer or ask an obvious question, (2) students are afraid of being considered as showing-offs if they respond to too much in class and (3) students think that their opinions are not worth sharing in class and are only comfortable to be shared with close friends. Hence, blended learning approach could reduce the fear and anxiety of asking questions in public.

With the presence of online discussion boards, learners were able to share freely in Blackboard. They may be evaluated by their peers who provide valuable feedback on their work without feeling challenged. In this way, learners could identify the areas for improvements whereas academics could monitor learners' progress by making use of peer review. This was shown by the number of posts and views of the site. Besides that, learners also agreed that the blended learning initiatives had also improved their accessibility and flexibility in their learning (item 1) such as reviewing the recorded videos whenever they need to. In addition, online assessments had also encouraged learners to practice more as they were allowed to perform multiple attempts on the assessment items and were able to receive prompt feedback. This had encouraged learners to learn independently (item 2) and helped to improve their understanding on the topics.

The findings also suggest that generally learners were neutral to the extent blended learning activities could motivate (item 3) them in learning. Many researches had shown that students' attention varies during lectures and thus, teachers need to develop ways to maintain student interest in the classroom [12]. With the use of iPad and Clickers, academics were able to capture learners' attention and enhance their engagement in class. The instruments were used to promote active learning through questions. Instead of verbal answers, learners provided their response anonymously in class. The use of iPad also enabled academics to move freely around the class and be approached by learners who may want to have a quick clarification on the topic but were reluctant to speak up. While academics intend to increase learners' motivation in learning, this requires learners to have discipline, maturity and continuous commitment in learning. As indicated by Marino, Eager \& Draxler [13], some students experienced difficulty adjusting to the structure of online courses, managing their time in such environments and maintaining self-motivation.

Moreover, the survey revealed that the activities designed for blended learning were interesting (item 4). Besides that, learners also indicated that they had the resources and technical ability to cope with online materials and activities (items 5 \& 6). Although not all new generations were tech savvy, the results obtained were expected as most learners considered themselves from a technology savvy generation. While most learners had an overall good experience with blended learning, some were concerned that this approach will increase their preparation time for class (Item 7). Generally, they still prefer to have academics delivering information to them directly rather than a flipped classroom model. This is evidenced by the lowest mean score 3.07 obtained in the survey (item 8). Lastly, some learners had expressed concerned on the fairness in grading of group assignments conducted online.

In conclusion, the learners' perceptions survey revealed that the factors of the acceptance of blended learning approach mainly depend on system functionality, technology self-efficacy, content feature, effective interaction and motivation as reported by $\mathrm{Wu}$, Tennyson \& Hsia [14].

\subsection{University's blended learning initiatives}

It is shown in the study that to facilitate blended learning in the university, academics and learners ought to have the shared vision, understanding and expectation in the adoption of the approach. Specifically there is a need to have a clear definition of blended learning. There are many different models of blended learning found [4,7] but the model adopted by the university was developed by Alammary, Sheard, \& Carbone [4]. In their model, three distinct design approaches were identified:

(1) Low-impact blend: adding extra activities to an existing course

(2) Medium-impact blend: replacing activities in an existing course

(3) High-impact blend: building the blended course from scratch.

Once the blended learning vision has been identified and recognized, it is essential to develop and reinforce plans for university to embark this new blended learning initiative. An academic practice team was established to lead this initiative and strategically address issues and challenges that may emerge during blended learning 
implementation. A blended learning site was also created in Blackboard to share information and resources in the faculty. Furthermore, the university also appointed faculty-based digital learning technologists to support technical development in the faculty. Recording rooms completed with necessary recording facilities were set up and recording software and relevant broadcasting system were identified and installed.

In order to facilitate blended learning, a minimum standard of Blackboard usage must be achieved. It is agreed that the LMS must be used to manage content effectively. The environment should be attractive and user friendly so that students can easily access the required information. Besides, information about assessments must be available and grade center should be utilized to provide timely feedback to class. Discussion board on Blackboard could also be used to create opportunities for interactions between learners-learners and instructor-learners. The activities created should also supplement and not overload the students as it has been reported that E-learning often suffers from making large amounts of information available for students to absorb independently [15].

\section{Conclusions}

The present study has several implications in education. First, it indicates that blended learning has the potential to meet learners' educational needs. The mixture of face-toface and online components in blended learning provides learners with the opportunities to learn from multiple delivery method. The overall learners' satisfaction survey also showed that blended learning increased student learning flexibility while maintaining social connections in the traditional classroom.

Secondly, the study indicates that academics were challenged to meet with the growing expectations required in blended learning. It is undeniable that an educator is a significant key to determine the success in the implementation of blended learning. Designing a blended delivery course requires time, effort, technical skills and clear pedagogical goal with the integration of technology. Consequently, there is a need to provide professional development program and support for academics.

In general, the findings also suggested that when implementing blended learning, various factors need to be considered. The factors to be considered by academics and learners are summarized in Table 3.

This study determines the readiness of academics and learners to embrace blended learning and the factors for successful implementation. Moving on, future studies would focus to evaluate the effectiveness and quality of blended learning approach in the university. Blended learning elements could be evaluated from the relationship between various factors such as learning outcomes, resources, content, assessments, delivery methods, pedagogy and learner's achievements. In addition, the context of the studies could be expanded to address the perceptions of internal (leaders and administration in education) and external (educational community) stakeholders. In conclusion, blended learning is a promising approach to facilitate learning experience with the condition that academics are willing to embrace change and commit in delivery strategy. Ultimately the goal is for academics to focus on pedagogy-based learning instruction to ensure success in blended learning approach.

Table 3. Factors to be considered in implementing blended learning.

\begin{tabular}{|c|l|l|}
\hline & \multicolumn{1}{|c|}{ Academic Staff } & \multicolumn{1}{c|}{ Learners } \\
\hline 1. & Definition \& Expectation & Definition \& Expectation \\
\hline 2. & Facilities & Facilities \\
\hline 3. & Time management & Time management \\
\hline 4. & $\begin{array}{l}\text { Technical development and } \\
\text { support }\end{array}$ & $\begin{array}{l}\text { Technical ability and } \\
\text { support }\end{array}$ \\
\hline 5. & $\begin{array}{l}\text { Online materials/resources } \\
\text { management }\end{array}$ & $\begin{array}{l}\text { Free riders/fairness in } \\
\text { grading }\end{array}$ \\
\hline 6. & $\begin{array}{l}\text { Stakeholders' expectation } \\
\text { (Professional bodies) }\end{array}$ & $\begin{array}{l}\text { Stakeholders' expectation } \\
\text { (Parents) }\end{array}$ \\
\hline
\end{tabular}

\section{References}

1. D.R. Garrison, H. Kanuka. IHE, 7(2), 95-105 (2004)

2. B. Means, Y. Toyama, R. Murphy, M. Bakia, K. Jones. Evaluation of evidence based practices in online learning: A meta-analysis and review of online learning studies. Washington, DC: U.S. Department of Education, Office of Planning, Evaluation, and Policy Development (2009)

3. E. Martinez-Caro, F. Campuzano-Bolarin. EJEE, 36(5), 473-483 (2011)

4. A. Alammary, J. Sheard, A. Carbone. AJET, 30(4), 440-454 (2014)

5. M. E. Blueprint. Blueprint 2015-2025. Ministry of Education Malaysia (2015)

6. R. Owston. IHE., 18, 1-3 (2013).

7. P. Moskal, C. Dziubna, J. Hartman. IHE, 18, 15-23 (2013).

8. A. Norberg, C. D. Dziuban, P.D. Moskal. A timebased blended learning model. On the Horizon, 19, 207-216 (2011)

9. K. F. Hew, T. Brush. ETRD, 55(3), 223-252 (2007)

10. J. Groff, C. Mouza. AACE J., 16(1), 21-46 (2008)

11. J. Y. Lee. IES, 4(2), 75-81 (2011)

12. K. Wilson, J.H. Korn. TOP, 34(2), 85-89 (2007).

13. T. A. Marino, M. Eager, T. Draxler. NTLF 9(4), 4-6 (2000)

14. J. H. Wu, R. D. Tennyson, T. L. Hsia. Comput Educ, 55(1), 155-164 (2010)

15. G. L. Waddoups, S. L. Howell. IRRODL, 2(2) $52 / 108$ (2002). 